\title{
PROGRAMA NACIONAL DE ACESSO AO ENSINO TÉCNICO E EMPREGO (PRONATEC): EXPANSÃO E PRIVATIZAÇÃO DA EDUCAÇÃO PROFISSIONAL
}

\author{
T. G. S. MELO* e D. H. MOURA \\ Instituto Federal de Educação, Ciência e Tecnologia do Rio Grande do Norte \\ tici.hp@gmail.com*
}

Artigo submetido em agosto/2016 e aceito em setembro/2016

DOI: $10.15628 /$ holos.2016.4995

\section{RESUMO}

Este artigo tem como finalidade desvelar a essência dos objetivos do Programa Nacional de Acesso ao Ensino Técnico e Emprego (Pronatec) e suas relações com a expansão, a privatização e a qualidade da Educação Profissional brasileira. Para a análise, adotamos como categorias teóricas a historicidade, a totalidade e a contradição, visando uma melhor compreensão do objeto de estudo. As categorias empíricas são a expansão, a privatização e a qualidade da Educação Profissional. Os resultados do estudo demonstram que há uma relação estreita entre o processo de expansão e a privatização da Educação Profissional por meio, principalmente, do Pronatec, pois há elevada oferta de matrículas através das parcerias público privadas com oferta abundante de cursos de curta duração e de baixa complexidade, que sinalizam para a dinamização de um mercado do campo da Educação Profissional e para a baixa qualidade dos cursos proporcionados à população pouco escolarizada.

PALAVRAS-CHAVE: Pronatec, Expansão da Educação Profissional, Privatização da Educação Profissional, Qualidade da Educação Profissional.

\section{NATIONAL PROGRAM FOR ACCESS TO TECHNICAL EDUCATION AND WORK (PRONATEC): EXPANSION AND PRIVATIZATION OF PROFESSIONAL EDUCATION}

\section{ABSTRACT}

This article aims to unveil the essence of the objectives of the National Program for Access to VocationalEducation and Employment (Pronatec) and its relations with the expansion, privatization and the quality of Brazilian Professional Education. The analysis used as theoretical categories: historicity, totality and contradiction. It directed to better comprehension of the study. The empirical categories are the expansion, privatization and the quality of Professional Education. The results
\end{abstract}

demonstrate that there is a narrow relation between the process of the expansion and the privatization of the Professional Education through, mainly, Pronatec. Thus, there is a high number of enrolment opportunities via public/private partnerships. Also, there is an abundant offer for short-term and low-complexity courses that point to the promotion of a market for the Professional Education and the low-quality courses provided for the population with a low-level of education.

KEYWORDS: Pronatec, Professional Education Expansion, Professional Education Privatization, Professional Education Quality. 


\section{INTRODUÇÃO}

Importantes ações voltadas para a Educação Profissional (EP) foram desencadeadas a partir dos anos finais da primeira década deste século, fundamentalmente, nos marcos da expansão e da privatização dessa esfera educacional. Nesse contexto, o Programa Nacional de Acesso ao Ensino Técnico e Emprego (Pronatec), criado pela Lei no $12.513 / 2011^{1}$, vem se consolidando como a principal política pública dessa esfera educacional, sendo considerada prioritária pelo governo do país.

O governo federal anuncia que, por meio desse Programa, proporcionou mais de 8 milhões de matrículas, no período de 2011 a 2015, com, aproximadamente, 2,3 milhões em cursos técnicos na forma concomitante e 5,8 milhões em cursos de formação inicial e continuada (FIC). Esses últimos de curta duração e com carga horária a partir de 160 horas.

Por outro lado, a expansão também ocorre por meio da criação de novos campi dos institutos federais de educação ciência e tecnologia, espaço em que se vem priorizando a oferta de cursos que integram o ensino médio à EP técnica de nível médio por meio do ensino médio integrado (EMI). A expansão da Rede Federal de EP (RFEP) é muito significativa. Segundo dados do $M C^{2}$, em 2002, essa rede era composta por 140 campi. Em 2015 já eram 578 campi distribuídos em todos os estados brasileiros e no Distrito federal, com unidades em 568 municípios. A previsão é de que, em 2016, se chegue a 644 campi.

Este artigo é fruto da pesquisa cujo foco era analisar e desvelar o papel do Pronatec nesse processo de expansão da EP brasileira em curso e foi desenvolvido a partir de revisão bibliográfica e análise documental, tendo como referencial teórico o pensamento sócio-histórico-crítico. Assim, analisamos a Lei no 12.513/2011, dados disponíveis no Portal do Ministério da Educação (MEC) e do Instituto Nacional de Pesquisas Educacionais Anísio Teixeira (INEP), o Relatório de Auditoria Anual de Contas/2013 realizado pela Controladoria Geral da União (CGU) na Secretaria de Educação Profissional e Tecnológica (SETEC) e o Relatório de Gestão do Exercício de 2013 da SETEC/MEC, além de dialogarmos com autores como Machado e Garcia (2013), Lima (2012), Lima Filho (2015), Saldanha (2012), Moura (2013) e Frigotto (2013), que analisam o Pronatec no contexto educacional brasileiro, na segunda década do século XXI.

O artigo está estruturado da seguinte forma: inicialmente, buscamos compreender o contexto da gênese do Pronatec; após isso, evidenciamos o discurso oficial e os primeiros movimentos do real no âmbito do Pronatec; em seguida, discutimos o fortalecimento do mercado da EP em detrimento da qualidade educacional; finalmente, serão apresentadas algumas reflexões conclusivas a respeito da temática abordada.

\section{PRONATEC: HISTÓRICO E CARACTERIZAÇÃO}

O Pronatec tem como objetivos declarados:

\footnotetext{
${ }^{1}$ Disponível em <http://www.planalto.gov.br/ccivil_03/_ato2011-2014/2011/lei/l12513.htm>. Acesso: 05.jun.2016

${ }^{2}$ Disponível em < http://redefederal.mec.gov.br/expansao-da-rede-federal>. Acesso: 05.jun.2016.
} 
I - expandir, interiorizar e democratizar a oferta de cursos de educação profissional técnica de nível médio presencial e a distância e de cursos e programas de formação inicial e continuada ou qualificação profissional; II fomentar e apoiar a expansão da rede física de atendimento da educação profissional e tecnológica; III - contribuir para a melhoria da qualidade do ensino médio público, por meio da articulação com a educação profissional; IV - ampliar as oportunidades educacionais dos trabalhadores, por meio do incremento da formação e qualificação profissional; V - estimular a difusão de recursos pedagógicos para apoiar a oferta de cursos de educação profissional e tecnológica. VI - estimular a articulação entre a política de educação profissional e tecnológica e as políticas de geração de trabalho, emprego e renda. (Incluído pela Lei no 12.816, de 2013) (BRASIL, 2011, p. 1).

Uma leitura superficial dos objetivos anunciados pode nos levar ao entendimento de que Programa traz aspectos muito positivos para a expansão e o fomento à EP. Não obstante, faz-se necessária uma análise mais profunda quanto aos fundamentos desse Programa, buscando ir além de sua aparência, ou seja, assumir a tarefa de desvelar a sua essência. A partir disso, questionamos: expandir para que e para quem? Fomentar para que e para quem? Na busca de respostas a essas inquietações, tentaremos elucidar a racionalidade que fundamenta o Pronatec.

Nos anos 2000 entraram em vigor a expansão da RFEP, o Programa Brasil Profissionalizado, o Projovem ${ }^{3}$ e o Proeja ${ }^{4}$. Entretanto, não resta dúvida que o Pronatec, desde seu lançamento, tem colocado a EP em uma posição de notoriedade em nível nacional. Vale salientar que a concepção expansionista e de gestão público-privada desse Programa tem suas bases não apenas no legado neoliberal da década de 1990 para educação brasileira. É imprescindível compreender que as raízes históricas do Pronatec são anteriores, posto que Machado e Garcia (2013) afirmam que o Programa retoma experiências, como por exemplo, o Programa Intensivo de Preparação de Mão de Obra $\left(\mathrm{PIPMO}^{5}\right)$, consolidado na Ditadura Civil-Militar. Também são evidentes suas conexões com o Plano Nacional de Qualificação do Trabalhador $\left(\operatorname{PLANFOR}^{6}\right)$, política de qualificação dos trabalhadores (mão de obra, segundo a lógica do Programa) adotada pelo governo FHC nos anos 1990. Ambos descolados da elevação de escolaridade, com predomínio de cursos de baixa carga horária e centrados nos interesses imediatos do denominado mercado de trabalho.

O Pronatec é criado e entra em vigor sob o discurso da falta de mão de obra qualificada. Em 28 de abril de 2011, no discurso de lançamento do Programa, a presidente Dilma Roussef ${ }^{7}$ afirmou que, em

\footnotetext{
${ }^{3}$ Programa Nacional de Inclusão de Jovens

${ }^{4}$ Programa Nacional de Integração da Educação Profissional com a Educação Básica na Modalidade de Educação de Jovens e Adultos

${ }^{5}$ Vigente de 1963 a 1982.

${ }^{6}$ Vigente de 1996 a 2002.

7 Divulgado no Portal Planalto. Disponível em http://www2.planalto.gov.br/acompanhe-oplanalto/discursos/discursos-da-presidenta/discurso-da-presidenta-da-republica-dilma-rousseff-durante-cerimoniade-lancamento-do-programa-nacional-de-acesso-ao-ensino-tecnico-e-ao-emprego. Acesso 05.jun.2016.
} 
[...] alguns casos, falta mão de obra qualificada, em outros, sobra mão de obra sem a qualificação necessária derivada das nossas necessidades, da indústria, do comércio, dos serviços, enfim, do sistema produtivo.

Dessa maneira, o Programa é justificado pelo discurso da necessidade da qualificação profissional dos trabalhadores, que ficou conhecido como apagão de mão de obra, decorrente de outro apagão, o educacional. De acordo com Frigotto (2013), a metáfora do apagão educacional, que reclama a falta de pessoal qualificado, é fruto da mentalidade colonizadora e escravocrata da classe dominante. Nesse contexto,

[...] os dados da Pnad mostram que apenas 9\% dos jovens entre 18 e 24 anos entram no curso superior. É claro que vão faltar, especialmente em algumas áreas, profissionais qualificados. Como nos últimos cinquenta anos avançamos de forma pífia no aumento quantitativo e na qualidade dos jovens que cursam o ensino médio na idade adequada, a maioria só atinge o ensino fundamental, e as políticas de formação profissional para grande massa de jovens e adultos estão na lógica da improvisação, da precarização e do adestramento (FRIGOTTO, 2013, s/n).

O autor se refere à Pesquisa Nacional por Amostra de Domicílios (Pnad) realizada em 2011. Vejamos que, na essência desse apagão, estão problemas educacionais anteriores, em que grande parte dos jovens brasileiros não encontra condições de vida adequadas para concluir o Ensino Fundamental e ingressar no Ensino Médio, nem tampouco ingressar no Ensino Superior. Na realidade, as empresas têm um excedente populacional à disposição, visto que existe um contingente significativo de pessoas trabalhando na informalidade. De acordo com o Instituto Brasileiro de Geografia e Estatística (IBGE), em 2014 o índice de desocupação atingiu 4,3\%.

Ao refletirmos sobre o discurso que faz a defesa da existência de um apagão de mão de obra e que delega à EP o poder de melhorar as condições de empregabilidade das pessoas, constatamos que, de fato, há uma retomada da Teoria do Capital Humano.

A Teoria do Capital Humano proposta por Schultz $(1973)^{8}$, vincula, de modo linear, educação, treinamento e desenvolvimento. Desse modo, segundo essa concepção, quanto maior for o grau de escolarização de uma nação, maior será seu desenvolvimento. Segundo, Frigotto (1999), essa teoria possui uma ideologia positivista e antagônica aos interesses da classe trabalhadora. Ademais, a Teoria do Capital Humano relaciona-se a

uma noção que os intelectuais da burguesia mundial produziram para explicar o fenômeno da desigualdade entre as nações e entre indivíduos ou grupos sociais, sem desvendar os fundamentos reais que produzem esta desigualdade: a propriedade privada dos meios e instrumentos de produção pela burguesia ou classe capitalista e a compra, numa relação desigual, da única mercadoria que os trabalhadores possuem para proverem os meios de vida seus e de seus filhos - a venda de sua força de trabalho (FRIGOTTO, 2009, p. 2).

Nessa teoria, se desconhecem as relações de poder construídas historicamente, reafirmando que os indivíduos, com origem e classe social distintas, possuem o mesmo poder de

\footnotetext{
${ }^{8}$ Sobre isso ler: SCHULTZ, T. O capital humano: investimento em educação e pesquisa.

Trad. de Marco Aurélio de M. Matos. Rio de Janeiro. Zahar, 1973. p. 31-52.
} 
escolha. Isso recai em um reducionismo das concepções de ser humano, trabalho, sociedade, educação e história (FRIGOTTO, 2009). Enquanto isso, a partir da perspectiva crítica e acompanhando Silva $(2015$, p. 26)

[...] ressaltamos que ideologicamente a Teoria do Capital humano explícita no Pronatec tem essa intenção implícita de fazer com que as pessoas acreditem que estão sendo criadas condições de igualdades de acesso a empregos por meio do Programa. Por outro lado, essa mesma crença propaga que se não houver a inserção no mercado de trabalho é em razão das seleções que só absorverem [sic] os "melhores profissionais", ou seja, a responsabilidade recai sobre os próprios sujeitos individualmente.

O discurso do apagão deflagra o intento de mascarar a real razão dessa falta de qualificação, ou seja, desconsidera o processo histórico desigual brasileiro. Estimulado por esse discurso do apagão de mão de obra, e influenciado pela Teoria do Capital Humano, o Pronatec é hoje o Programa que orienta a EP.

A pressão empresarial por qualificação profissional também faz parte desse contexto de criação do Pronatec. O Estado lança respostas a essa pressão que, de acordo com Lima (2012), são repassados ao Estado os custos que o empresariado teria com a qualificação profissional. Essa transferência de responsabilidade é socialmente aceita e mascarada pelo discurso da participação estatal na educação dos trabalhadores.

O Estado atende duplamente às necessidades dos donos do capital. Primeiro, qualifica minimamente os trabalhadores para atender às demandas do mercado e, segundo, reduz seus custos com a qualificação profissional. Refletimos que, a partir de concepções neoliberais ${ }^{9}$, 0 Estado, além da função reguladora, assume a função de financiador. A partir das orientações neoliberais acerca do papel Estado, que priorizam a esfera privada, o Pronatec foi concebido e vem sendo implementado, predominantemente, com esse sentido.

De modo geral, o Pronatec oferece cursos de EP Técnica de Nível Médio (presencial e à distância) e cursos FIC. Os primeiros são orientados por suas respectivas diretrizes curriculares nacionais definidas pelo Conselho Nacional de Educação, tendo cargas horárias que variam de 800 a 1200h, conforme o eixo tecnológico em que se insira. Já os cursos FIC possuem carga horária mínima de 160 horas, conforme já mencionamos anteriormente.

Segundo o Guia Pronatec de Cursos FIC (2013), são ofertados 644 cursos distintos. Pensadas as questões mais introdutórias, a respeito da criação do Pronatec, na próxima seção avançaremos no sentido de perceber seus movimentos iniciais.

\footnotetext{
${ }^{9}$ De acordo com Draibe (1993), o neoliberalismo constitui um conjunto de ações destinadas à reforma do Estado e das suas políticas. Como consequência do neoliberalismo, as políticas sociais tornam-se cada vez mais compensatórias, orientadas pelos princípios de privatização, focalização, desregulamentação estatal, eficácia, eficiência e reestruturação da produção e do trabalho. Por meio dessas políticas também são evidenciadas tensões entre as esferas pública e privada.
} 


\section{PRONATEC: O DISCURSO OFICIAL E OS PRIMEIROS MOVIMENTOS DO REAL}

Para responder às perguntas (expandir para que e para quem? Fomentar para que e para quem?), procuramos os dados da oferta de matrícula do Programa. Inicialmente, buscamos no próprio sítio do INEP, mas não existem dados específicos do Pronatec. A partir daí, solicitamos ao Ministério da Educação, por meio do Sistema Eletrônico do Serviço de Informação do Cidadão ${ }^{10}$, em fevereiro de 2015, dados específicos do Programa. No mês seguinte ao pedido, recebemos a resposta afirmando que,

Das mais de 8 milhões de matrículas já realizadas pelo Pronatec, cerca de $30 \%$ foram realizadas em cursos técnicos e, o restante, em cursos de formação inicial e continuada. Quanto às vagas em cursos técnicos, a participação da Rede Federal no Pronatec é de $31 \%$, a do SENAI $20 \%$, a das instituições privadas que aderiram ao SISUTEC $19 \%$, a do SENAC $15 \%$ e a das redes estaduais $15 \%$. Os demais ofertantes de cursos técnicos são responsáveis por 0,01\% da oferta. Quanto às matrículas em cursos de formação inicial e continuada, a participação da Rede Federal no Pronatec é de $8 \%$, a do SENAI $48 \%$, a do SENAC $38 \%$ e a das redes estaduais $2 \%$. Os demais ofertantes são responsáveis por $4 \%$ da oferta.

Destarte, o número de matrículas de mais de 8 milhões em pouco mais de três anos de Programa, coaduna com a perspectiva expansionista da EP brasileira, via Pronatec. Apesar da superficialidade das informações proporcionadas pelo MEC, já podemos concluir que é prioritária a oferta dos cursos FIC, de curta duração e desvinculados da elevação de escolaridade, os quais abarcaram $70 \%$ da matrícula. Isso já constitui um indicador importante do comprometimento da qualidade educacional no âmbito desse Programa, ao menos, quando adotamos como referência a concepção de formação integral dos sujeitos.

Vale salientar, que solicitamos ao MEC dados mais detalhados sobre a EP em geral sobre o Programa, como número de matrículas anuais separados por oferta (Concomitante, Subsequente, Integrado e FIC), e por dependência administrativa, pública e privada. A ideia era construir um quadro com toda a oferta da EP no qual pudesse ser identificada a parcela correspondente exclusivamente ao Pronatec, destacando a matrícula pública e a privada, assim como os dados de conclusão.

Apesar do esforço, não conseguimos alcançar nosso intento, pois a resposta dada foi muito geral, evidenciando falhas no monitoramento, obstaculizando a transparência dos dados do Programa. A ausência desses dados dificulta uma análise mais fidedigna da distribuição das matrículas do Pronatec, principalmente no tocante à distribuição entre a oferta pública e a privada. Mais grave ainda é a falta de informações sobre dados de conclusão dos cursos, o que impede avaliar a eficácia do Programa, mesmo a partir de sua limitada concepção de formação humana. A impossibilidade de análise da evolução da participação de cada tipo de instituição ofertante ao longo dos anos impossibilita que o Programa seja analisado em profundidade.

\footnotetext{
${ }^{10}$ O Sistema Eletrônico do Serviço de Informação do Cidadão (e-SIC) possibilita o encaminhamento de pedidos de acesso à informação aos órgãos e entidades do Executivo Federal.
} 
Considerando a resposta superficial dada pelo MEC, buscamos outras fontes para subsidiar a análise. Nessa busca, tivemos acesso ao Relatório de Auditoria Anual de Contas $/ 2013^{11}$ realizado pela CGU na SETEC/MEC e o Relatório de Gestão do Exercício 2013 da SETEC/MEC ${ }^{12}$. A partir daí, extraímos dados importantes que nos possibilitam arguir a respeito da distribuição e da expansão da oferta da EP via Pronatec. Observemos a Tabela 1.

Tabela 1: Vagas ofertadas por meio do Pronatec de 2011 a 2014, segundo Relatório de Gestão da SETEC/MEC/2013

\begin{tabular}{|c|c|c|c|c|c|c|}
\hline \multicolumn{2}{|c|}{ Cursos Técnicos } & 2011 & 2012 & 2013 & $2014^{13}$ & Total \\
\hline \multirow{2}{*}{$\begin{array}{l}\text { Bolsa- } \\
\text { Formação }\end{array}$} & Previsto & 9.415 & 99.149 & 151.313 & \multirow[t]{2}{*}{151.313} & 411.190 \\
\hline & Realizado & 0 & 101.541 & 304.966 & & 406.507 \\
\hline \multirow{2}{*}{$\begin{array}{l}\text { Brasil } \\
\text { Profissionaliz } \\
\text { ado }\end{array}$} & Previsto & 33.295 & 90.563 & 172.321 & \multirow[t]{2}{*}{233.781} & 529.960 \\
\hline & Realizado & 82.823 & 79.770 & 70.355 & & 232.948 \\
\hline \multirow[t]{2}{*}{ E-TEC } & Previsto & 74.000 & 150.000 & 200.000 & \multirow[t]{2}{*}{250.000} & 674.000 \\
\hline & Realizado & 75.364 & 134.341 & 137.012 & & 346.717 \\
\hline \multirow{2}{*}{$\begin{array}{l}\text { Acordo } \\
\text { Sistema S }\end{array}$} & Previsto & 56.416 & 76.119 & 110.545 & \multirow[t]{2}{*}{161.389} & 404.469 \\
\hline & Realizado & 85.357 & 102.807 & 132.289 & & 320.453 \\
\hline \multirow{2}{*}{$\begin{array}{l}\text { Rede Federal } \\
\text { de EРCT }\end{array}$} & Previsto & 72.000 & 79.560 & 90.360 & \multirow[t]{2}{*}{101.160} & 343.080 \\
\hline & Realizado & 117.621 & 119.274 & 121.958 & & 358.853 \\
\hline \multicolumn{2}{|l|}{ CURSOS FIC } & 2011 & 2012 & 2013 & 2014 & TOTAL \\
\hline \multirow{2}{*}{$\begin{array}{l}\text { Bolsa- } \\
\text { Formação }\end{array}$} & Previsto & 226.421 & 590.937 & 743.717 & \multirow[t]{2}{*}{1.013 .027} & 2.574 .102 \\
\hline & Realizado & 22.876 & 531.101 & 1.243 .047 & & 1.797 .024 \\
\hline \multirow{2}{*}{$\begin{array}{l}\text { Acordo } \\
\text { Sistema S }\end{array}$} & Previsto & 421.723 & 570.020 & 821.965 & \multirow[t]{2}{*}{1.194 .266} & 3.007 .974 \\
\hline & Realizado & 582.931 & 733.223 & 844.581 & & 2.160 .735 \\
\hline \multicolumn{2}{|c|}{$\begin{array}{l}\text { Total de Vagas Ofertadas: } \\
\text { Técnico + FIC }\end{array}$} & 966.972 & 1.802 .057 & 2.854 .208 & 3.104 .936 & 5.922 .869 \\
\hline
\end{tabular}

Fonte: Brasil (2014b).

Sobre a Tabela 1 é importante tecer várias considerações. Primeiramente cabe destacar a distorção entre seus dados e as informações prestadas pelo MEC à consulta por nós formulada. A diferença no que se refere à matrícula total é significativa. Segundo a Tabela 1, a matrícula total de 2011 a 2014 foi de 5.922.869, enquanto a informação do MEC em fevereiro de 2015 foi de que a matrícula total foi de cerca de 8 milhões. Isso corrobora o que já afirmamos antes sobre a falta de transparência dos dados do Pronatec por parte do poder público.

\footnotetext{
${ }^{11}$ Esse relatório apresenta os resultados dos exames realizados sobre a prestação de contas anual apresentada pela Secretaria de Educação Profissional e Tecnológica do Ministério da Educação - SETEC, realizado pela Controladoria Geral da União. O mesmo, teve foco no ano de 2013. Todavia o mesmo só foi disponibilizado no ano de 2014, sendo assim, foram inclusas as vagas realizadas até a elaboração do relatório, no ano de 2014.

12 Relatório apresentado aos órgãos de controle interno e externo como prestação de contas anual da SETEC/MEC. Ademais são evidenciados planejamento e resultados alcançados pela SETEC, a programação orçamentária e financeira, estrutura de governança da SETEC e execução orçamentária e financeira da SETEC, tratamento das deliberações dos órgãos de controle.

${ }^{13}$ Os dados de 2014 são estimativas, já que o Relatório é de 2013. Até a conclusão deste artigo não conseguimos os dados de matrículas detalhadas de 2014 e de 2015. No sítio do MEC (http://portal.mec.gov.br/index.php?option=com_docman\&view=download\&alias=22191-caderno-de-estudos-24inclusao-produtiva-urbana-pdf\&category_slug=setembro-2015-pdf\&Itemid=30192) encontramos que de 2011 a 2014 a matrícula total foi de 8,1 milhões, sendo 5,8 milhões em cursos FIC e 2,3 milhões em cursos técnicos de nível médio. Também No sítio do MEC (http://portal.mec.gov.br/pronatec) tem a informação de que de 2011 a 2015 a matrícula total foi de 9,4 milhões.
} 
Além disso, a Tabela 1 contabiliza como sendo do Pronatec, as matrículas do Programa Brasil Profissionalizado, criado em 2007, do acordo de gratuidade com o sistema " $\mathrm{S}$ " ${ }^{14}$, de 2008, e a matrícula da RFEP, que tem mais de 100 anos de existência. Ora, o MEC tenta plantar a ideia de que todo o esforço da centenária RFEP na oferta de cursos técnicos seja, na atualidade, creditada ao Pronatec, negando a própria construção e constituição histórica dessa Rede.

Evidentemente, as matrículas correspondentes a essas ofertas não poderiam ser contabilizadas como sendo do Pronatec. A rigor, a oferta Pronatec restringe-se àquelas decorrentes do Fundo de Financiamento do Ensino (Fies) e da concessão da bolsa-formação (estudante e trabalhador), aproximadamente 1,8 milhões em cursos FIC e 400 mil em cursos técnicos, conforme a própria Tabela 1.

Não obstante, o governo criou mecanismos para vincular a oferta de vários desses programas pré-existentes ao Pronatec. Ou seja, a estratégia é política no sentido de transformar o Pronatec em um imenso guarda-chuvas que vai abarcar toda a oferta da EP. Sobre isso, concordamos com Lima Filho, para quem

[...] programas importantes como o Brasil Profissionalizado (que apoia a ampliação das redes estaduais), o Programa Nacional de Integração da Educação Profissional com a Educação Básica na Modalidade de Educação de Jovens e Adultos (Proeja), a própria expansão dos institutos federais e sua oferta de educação básica e superior são diretamente afetados, uma vez que, submetidas à obrigatoriedade de oferta do Pronatec, as instituições e redes públicas desviam o foco e a ação de programas e modalidades educacionais mais consistentes que vinham sendo executados, por exemplo, a oferta do ensino médio ou da educação profissional integrada à educação básica. (LIMA FILHO, 2015, p. 210).

O autor alerta-nos para a subsunção de programas e ações governamentais orientadas pela lógica da integração entre educação básica (EB) e EP aos ditames do Pronatec que se move em direção contrária à integração. Esse novo foco, sinaliza que o esforço desenvolvido na primeira década do século XXI pelos segmentos progressistas da EP e por frações da estrutura de gestão do MEC, por meio de programas como o Brasil Profissionalizado e Proeja, ficam submetidos à oferta Pronatec, desviando a direção da integração entre EP e EP.

Então, por que o MEC tem creditado ao Pronatec toda a oferta da EP? Temos algumas inferências que justificam essa atribuição. Isso envolve, a noção de abrangência do Programa, pois quanto maior o número de matrículas a ele atribuídas, maior será sua importância como política pública de larga escala, mesmo que os dados não correspondam ao número real de matrículas.

A elevada matrícula atribuída ao Pronatec, também favorece ao aumento de pactos com possíveis ofertantes do Programa, no âmbito público e, principalmente, no privado. Essa absorção indevida de matrículas da EP pelo Pronatec, atrai novos ofertantes, fazendo com que o Programa se torne, do ponto de vista quantitativo, a principal iniciativa para a EP brasileira, propiciando que o empresariado cada vez mais com ele se envolva e se beneficie.

\footnotetext{
${ }^{14}$ Sobre esse acordo consultar: <http://mte.jusbrasil.com.br/noticias/166055/sistema-s-ampliara-a-gratuidade-e-onumero-de-vagas-em-cursos-tecnicos $>$.
} 
Outro aspecto corresponde a uma resposta social, justificando o capital estatal investido no Programa. Implicitamente, há também a necessidade de subsumir as tentativas progressistas de integrar elevação de escolaridade e formação profissional, que vinham (e ainda vêm, mas com um ritmo mais lento) sendo construídas a partir da primeira década do século XXI.

\section{O FORTALECIMENTO DO MERCADO PARA A EDUCAÇÃO PROFISSIONAL EM DETRIMENTO DA QUALIDADE EDUCACIONAL}

Para além da discriminação do número de matrículas, é necessário investigar a distribuição de recursos envolvida no Pronatec.

A Tabela 2, retirada do Relatório de Auditoria Anual de Contas/2013 realizado pela CGU na SETEC/MEC, evidencia o repasse para os ofertantes do Pronatec.

Tabela 2: Transferências anuais às instituições ofertantes, 2011 a maio/2014.

\begin{tabular}{|c|c|c|c|c|c|}
\hline $\begin{array}{l}\text { Rede de } \\
\text { Ensino }\end{array}$ & 2011 (R\$) & 2012 (R\$) & 2013 (R\$) & 2014 (R\$) & $\begin{array}{l}\text { Total por Rede de } \\
\text { Ensino (R\$) }\end{array}$ \\
\hline Sistema $\mathrm{S}^{15}$ & $208.261 .704,50$ & $1.054 .161 .444,18$ & $2.065 .021 .070,00$ & $1.200 .822 .145,00$ & $4.528 .266 .363,68$ \\
\hline $\begin{array}{l}\text { Rede } \\
\text { Federal }\end{array}$ & $39.827 .005,00$ & $338.789 .930,90$ & $742.501 .736,80$ & $193.924 .454,25$ & $1.315 .043 .126,95$ \\
\hline $\begin{array}{l}\text { Rede } \\
\text { Estadual }\end{array}$ & - & $92.648 .000,00$ & $228.482 .150,00$ & $83.393 .000,00$ & $404.523 .150,00$ \\
\hline $\begin{array}{l}\text { Rede } \\
\text { Municipal }\end{array}$ & - & - & $14.681 .000,00$ & $3.380 .000,00$ & $18.061 .000,00$ \\
\hline $\begin{array}{l}\text { Rede } \\
\text { Privada }\end{array}$ & - & - & $51.681 .163,63$ & $138.113 .463,01$ & $189.794 .626,64$ \\
\hline Total anual & $248.088 .709,50$ & $1.485 .599 .375,08$ & 3.102.367.120,43 & $1.619 .633 .062,26$ & $6.455 .688 .267,27$ \\
\hline
\end{tabular}

Fonte: FNDE (2014a) $)^{16}$

As transferências de 2011 a 2014 somam quase 6.5 bilhões de reais. Desse montante, 1.8 bilhões destinaram-se à esfera pública e 4,7 bilhões à privada, ou seja, $73 \%$ dos recursos do Pronatec são repassados ao capital privado, e apenas $27 \%$ à esfera pública.

Essas transferências vultosas de recursos públicos à iniciativa privada tem a função de dinamizar o mercado específico da EP em detrimento da educação pública.

Neste sentido, Saldanha (2012, p. 7), aponta que o Pronatec, "[...] sugere a incapacidade da escola pública em absorver a demanda potencial de alunos e sua futura inserção no mercado de trabalho [...]". Nos objetivos desse Programa, já evidenciados, anuncia-se a necessidade do Pronatec para a melhoria do Ensino Médio Público. Ao contrário disso, evidenciamos um efetivo fortalecimento da esfera privada. Assim, o Programa caminha no sentido contrário de um de seus principais objetivos anunciados.

\footnotetext{
${ }^{15}$ O Sistema S é composto por: Serviço Nacional de Aprendizagem Industrial (Senai); Serviço Social do Comércio (Sesc); Serviço Social da Indústria (Sesi); e Serviço Nacional de Aprendizagem do Comércio (Senac). Existem ainda os seguintes: Serviço Nacional de Aprendizagem Rural (Senar); Serviço Nacional de Aprendizagem do Cooperativismo (Sescoop); e Serviço Social de Transporte (Sest).

${ }^{16}$ Os dados utilizados pelo Relatório de Auditoria Anual de Contas/2013 realizado pela CGU na SETEC/MEC, foram encontrados no Fundo Nacional de Desenvolvimento da Educação (FNDE).
} 
Nesse contexto de fortalecimento do mercado privado de EP via Pronatec, é notória a posição privilegiada do Sistema "S". Esse é o maior sistema brasileiro voltado para a EP, por meio da qualificação básica, cursos técnicos de nível médio, cursos superiores de tecnologia e, inclusive, pós-graduação. Sua arrecadação é proveniente do repasse de empresas do setor em que cada "S" se situa, mas também há significativa arrecadação compulsória por meio de recursos oriundos da previdência social (GRABOWSKI, 2010).

Sua gênese encontra-se na criação do Sistema Nacional de Aprendizagem Industrial (SENAI), em 1942, que passou a ocupar um protagonismo na formação dos operários (CUNHA, 2000). Na tentativa de compreendermos melhor o funcionamento do Sistema S, elucidamos que

[...] o Artigo 240 da Constituição Federal de 5 de outubro de 1988 (CF/88), acomoda as peculiaridades dos Serviços Sociais Autônomos e reconhece de forma expressa que os mesmos são privados, titulares de receitas compulsórias próprias e que estão vinculados ao sistema sindical a que se refere o art. 8 o da CF/88, agasalha ainda toda a legislação infraconstitucional que reconhece a gestão privada dessas entidades. Assim, devido à natureza de suas fontes de custeio, denominados de recursos parafiscais, por força constitucional, tais entidades, como qualquer pessoa física ou jurídica, pública ou privada, que recebe recursos públicos, devem prestar contas da verba recebida, sujeitando-se, assim, ao controle do Tribunal de Contas, conforme exige o parágrafo único do art. 70 da CF/88 (LÔBO, 2013, p. 3).

Lôbo (2013) afirma que o fato dos recursos destinados ao Sistema " $S$ " serem denominadas parafiscais resulta em consequências, tais como a flexibilização na fiscalização, visto que não se aplica igual rigor que nas instituições públicas, causando confusão sobre a natureza pública ou privada dessas organizações.

Assim, ao longo da história, o Sistema "S" vem se fortalecendo com o subsídio público e formando a classe trabalhadora segundo os interesses do capital, em detrimento do que interessa à classe trabalhadora. Com o advento do Pronatec, o Estado brasileiro concede mais uma vez, a esse Sistema (e a outros segmentos privados) o direito de decidir sobre a concepção da formação destinada à classe trabalhadora, com subsídio do fundo público.

Uma das ações, no âmbito do Pronatec, que materializa essa lógica de transferência de recursos públicos para o privado sob a denominação de parceria público privado é a oferta da Bolsa-Formação (estudante e trabalhador). A Bolsa-Formação Estudante é destinada aos cursistas de EP Técnica de Nível Médio e para cursos de formação de professores em nível médio na modalidade normal. Já a Bolsa-Formação Trabalhador, é destinada ao próprio trabalhador, bem como às pessoas que participam dos programas federais de transferência de renda que realizam os cursos FIC (BRASIL, 2013). Como o maior número de matrículas encontra-se nos cursos FIC, há um público alvo delineado pelo Pronatec: os participantes dos programas de transferência de renda, principalmente.

Segundo a Lei no 12.513/2011, o Pronatec atenderá como público prioritário:

I - estudantes do ensino médio da rede pública, inclusive da educação de jovens e adultos; II - trabalhadores; III - beneficiários dos programas federais de transferência de renda; e IV - estudante que tenha cursado o ensino médio 
completo em escola da rede pública ou em instituições privadas na condição de bolsista integral, nos termos do regulamento. (BRASIL, 2011, p. 1).

Devido à oferta da Bolsa Formação - recurso destinado às empresas para a manutenção dos cursos Pronatec - parte desse montante é entregue ao aluno, atraindo grande contingente da população que participa dos programas de transferência de renda. Esse aspecto sinaliza para a tendência de manutenção da condição subalterna dessa população, atenuando as legítimas necessidades da classe trabalhadora por educação, por meio de respostas pragmáticas, como os cursos de curta duração que retomam perspectivas duais da EP. São esses os sujeitos que estão matriculados nos cursos FIC oferecidos pela iniciativa privada no âmbito do Pronatec, incluindo, o Sistema "S", reiterando a máxima da "educação pobre para o pobre".

A respeito da Bolsa-Formação, a Tabela 3, evidencia sua distribuição por rede ofertante e por cursos FIC e técnicos.

Tabela 3: Número absoluto de beneficiários do Pronatec Bolsa-Formação, distribuídos por rede ofertante e por cursos FIC e técnicos, 2011 a maio/2014.

\begin{tabular}{|l|l|l|l|}
\hline Instituições Ofertantes & Curso FIC & Técnico & Total Geral \\
\hline SENAI & 978.189 & 173.792 & 1.151 .981 \\
\hline SENAC & 781.633 & 78.995 & 860.628 \\
\hline SENAT & 133.058 & 247 & 133.305 \\
\hline SENAR & 82.313 & - & 82.313 \\
\hline Rede Privada & - & 292.550 & 292.550 \\
\hline Rede Federal & 425.482 & 21.831 & 447.313 \\
\hline Rede Estadual & 99.038 & 54.277 & 153.315 \\
\hline Rede Municipal & - & 462 & 462 \\
\hline Total Geral & 2.499 .713 & 622.154 & 3.121 .867 \\
\hline
\end{tabular}

Fonte: adaptado de Brasil (2014b)

Os dados do Relatório de Gestão do Exercício de 2013 da SETEC/MEC evidenciam que o maior número de bolsas financiadas pelo Pronatec está nos cursos FIC oferecidos pela iniciativa privada (80\%), principalmente, pelo Sistema "S" (70,6\%). Esses cursos apresentam uma carga horária mínima de 160 horas e máxima de 400. Então, de acordo com Lima (2012, p. 504, grifo nosso),

[...] este aspecto é bastante temerário, pois joga a EP no processo de mercantilização, visto que as empresas que vão financiar bolsas podem optar preferencialmente ou exclusivamente por cursos técnicos não integrados, ou formas de qualificação mais rápidas e focadas nos seus processos produtivos, jogando o papel mediador da educação no pragmatismo do imediatismo. Por outro lado, pode vir a consolidar um mercado, já bem forte, de oferta paga e privada de EP.

Observamos então, mais uma vez, que a maioria dos cursos oferecidos pelo Pronatec, são de curta duração. E o que é mais grave, como os cursos de maior complexidade, os técnicos, são oferecidos por meio da concomitância, implicando em dupla jornada escolar para os cursistas, reduz-se a possibilidade de que os trabalhadores a eles tenham acesso. Assim, esses sujeitos são atraídos pelas ofertas aligeiradas sob o falso discurso oficial de que tais cursos vão contribuir para a melhoria da empregabilidade. 
Contrariamente a isso, estudos desenvolvidos por organizações vinculadas aos próprios interesses empresariais constatam que esses cursos aligeirados não têm a capacidade de atender ao que sinaliza o mercado. E, segundo pesquisa desenvolvida pela Fundação Getúlio Vargas (FGV, 2010), com relação à empregabilidade, o efeito desses cursos de curta duração é, em geral, baixo e "no caso dos cursos de informática o efeito é negativo, com chances $14.1 \%$ menores em relação à base dos que nunca frequentaram". (p. 23). Isso ratifica, a lógica da precarização da qualidade educacional embutida no Pronatec.

No que se refere aos cursos técnicos, a oferta ocorre em sentido contrário à integração entre o Ensino Médio e a EP, retomando a proposta do Decreto no 2.208/1997 ${ }^{17}$ (LIMA, 2012), uma vez que a Bolsa-Formação Estudante financia cursos técnicos concomitantes. Além disso, de acordo com a Tabela 3, apenas $12,3 \%$ das bolsas repassadas a estudantes de cursos técnicos ocorreu na esfera pública, precisamente o espaço onde há a maior oferta do EMI. Enquanto isso, $87,7 \%$ dessas bolsas foram destinadas à iniciativa privada, onde a oferta do EMI é insignificante. Isso na prática, representa um forte incentivo ao crescimento da oferta concomitante em detrimento da integrada.

Guimarães (2014) traz dados importantes sobre o repasse da Bolsa-Formação, afirmando que a Anhanguera-Kroton ${ }^{18}$, maior empresa educacional do mundo, possui 35 mil alunos em cursos técnicos via Pronatec. A Anhanguera-Kroton e o MEC não responderam sobre o recurso total repassado da União para a empresa. Entretanto, foi informado que o recurso repassado por aluno, mensalmente, é cerca de $\mathrm{R} \$ 450,00$, que multiplicado por 35 mil (número de matrículas na Anhanguera-Kroton) nos permite chegar ao valor de $\mathrm{R} \$ 15,7$ milhões por mês ou $\mathrm{R} \$ 189$ milhões no período de um ano (GUIMARÃES, 2014).

Esse favorecimento ao setor empresarial, na realidade, faz parte da lógica estruturante do Programa que, embora não seja explicitado, tem como uma das bases a dinamização e o fortalecimento do mercado da EP, tudo isso em sintonia com o contexto global.

Ainda na perspectiva de perceber estratégias que promovem a transferência de recursos públicos para a esfera privada, observamos que a Lei no 12.513 promoveu mudança importante no Fundo de Financiamento ao Estudante do Ensino Superior (Fies), que passou a denominar-se Fundo de Financiamento Estudantil, continuando com a mesma sigla. Essa ação promove o acesso ao Fies de estudantes na EP técnica de nível médio da esfera privada.

Dessa forma, o Fies também é um dos mecanismos de transferência de recurso público para a esfera privada da EP. Imprimindo ao Pronatec, uma lógica mercadológica muito forte. Moura (2013, p. 24, grifo nosso), sinaliza dois objetivos sobre essa modificação do Fies, são eles:

O primeiro, e mais óbvio, é o de dinamizar o mercado da EP, estimulando a criação ou a adequação de empresas para competir ou intensificar a competição nesse segmento do mercado educacional. O segundo é um pouco mais complexo, mas

\footnotetext{
17 Decreto que eliminou a possibilidade de integração entre o Ensino Médio e a EP Técnica de Nível Médio.

${ }^{18}$ Compreende a fusão dos grupos privados de educação Anhanguera e Kroton. Essa fusão, criou a 17ạ maior empresa da

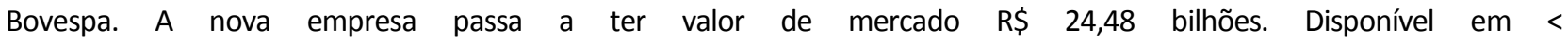
http://g1.globo.com/economia/mercados/noticia/2014/07/fusao-da-anhanguera-e-kroton-cria-17-maior-empresada-bovespa.html>. Acesso: 1 jun. 2015
} 
igualmente coerente com toda a racionalidade que está na gênese desse Programa. O novo FIES torna possível a existência de empresas educacionais com um modelo semelhante ao dos institutos federais, pois uma organização privada de ensino superior pode se cadastrar nesse fundo e passar a atuar na oferta de cursos técnicos de nível médio.

Nos dois objetivos elencados, o Fies possibilita a criação e a dinamização da oferta de cursos de EP privados, a exemplo do que já fora criado para as empresas educacionais no Ensino Superior. Ou seja, a formação profissional, passa a ser considerada uma mercadoria, por meio da liberação de financiamentos concedidos pelo Fies.

Outrossim,

[...] frente à crise do capitalismo contemporâneo e à descontinuação da esfera pública, constituiu-se um padrão de financiamento público da economia privada capitalista. A partir de regras universais e globais, que são pactuadas, o fundo público passou a financiar a acumulação capitalista (GRABOWSKI, 2010, p. 77).

O Pronatec segue esse padrão mencionado por Grabowski (2010), o qual está claramente presente no atual PNE (2014-2024), aprovado pela Lei $n=13.005^{19}$. Por um lado, o PNE contempla uma luta histórica dos educadores progressistas ao fixar a obrigatoriedade da destinação de $10 \%$ do PIB para a educação pública, mas, o mesmo Plano, por outro lado, estabelece que dentro desses $10 \%$ vinculados à educação pública poderão ser contabilizados recursos destinados aos programas de expansão da EP (atualmente, o Pronatec) e da educação superior (atualmente, o Prouni), além do Fies, na forma de incentivo e isenção fiscal. Isso efetiva e legitima a participação privada no montante do orçamento com destinação pública.

Nesse sentido, vale salientar, segundo Neves (2008, p. 185), que no Brasil, as políticas para a educação se "[...] consubstanciam com a lógica do mercado em uma dupla e concomitante direção, a da consolidação do mercado do conhecimento e a do aprofundamento do conhecimento para o mercado."

É necessário refletirmos sobre esse mercado do conhecimento. Neves (2008), argumenta que a consolidação do mercado do conhecimento avança por meio de uma política educacional que torna a escola cada vez mais dependente do capital, ou seja, em que seus pressupostos científico-filosóficos alinham-se à consolidação de um mercado educacional.

Com tudo isso, entendemos que o conhecimento e a formação profissional, propriamente dita, sejam utilizados como mercadorias nesse mercado do conhecimento. Esse mercado se materializa, a partir do momento que grandes empresas se apropriam do espaço educacional, por um lado ofertando cursos com o menor custo possível, e por outro com a maior rentabilidade possível. Ademais, o mercado do conhecimento evidencia preferência por cursos aligeirados, em menor tempo possível, com salas utilizadas com capacidade máxima de alunos e altos índices na relação aluno/professor. Há também a produção e utilização de materiais didáticos padronizados, em que o educando muitas vezes limita-se a este acervo disponibilizado pelas empresas. Isso acaba por alimentar em vários aspectos o mercado do conhecimento.

${ }^{19}$ Disponível em < http://www.planalto.gov.br/ccivil_03/_ato2011-2014/2014/lei/l13005.htm>. Acesso: 06.Jun.2015. 
Por meio do Pronatec, observamos, de fato, a formação de um mercado do conhecimento para a EP. Além dos elevados valores repassados a um único grupo empresarial, como os recursos destinados à Anhanguera-Kroton, temos outro exemplo, a New Education (2014). Essa, se constitui em uma empresa que se propõe a ofertar cursos para outras empresas educacionais sobre como implantar o Pronatec. No sítio da New Education $(2014)^{20}$ é feita uma propaganda muito positiva para que as "empresas educacionais" possam aderir ao Programa. Na concepção dessa assessoria, o Pronatec resolve problemas como espaços ociosos, otimiza custo-benefício, fortalece a marca da empresa vinculada e proporciona o crescimento rápido da escola. Os cursos de assessoria são ofertados no próprio sítio, à distância.

Enfim, o discurso da expansão da EP, via Pronatec, vem “[...] 'pseudocriando' o direito à educação e escondendo a formação para o mercado para, no final das contas, criar o mercado da formação. (LIMA, 2012, p. 497, grifo do autor). Com a possibilidade do acesso aos cursos, engendra-se a falsa noção de democratização do acesso à EP.

\section{CONSIDERAÇÕES FINAIS}

Por toda a análise desenvolvida, concluímos que o Pronatec tem contribuído para a dinamização do mercado do conhecimento assim como para o aprofundamento do conhecimento sobre o mercado, conforme Neves (2008) e Lima (2012). Nesse caminho, apresenta como resultado a produção em larga escala de um contingente de trabalhadores com baixa escolaridade, privada de uma formação geral, para alimentar o desenvolvimento subalterno, desigual e combinado brasileiro. Foi concebido e é executado com base na função do Estado de contribuir para a reprodução do capital, nesse caso, por meio de uma educação que forma os fragmentos da classe trabalhadora por caminhos distintos, contribuindo também para perpetuar a divisão técnica do trabalho e, em consequência, a separação entre trabalho intelectual e manual, alimentos vitais do modo de produção capitalista.

No Pronatec também está presente a função legitimadora do estado frente ao capital, de caráter ideológico, que de acordo com O'Connor (1977), volta-se para manutenção da harmonia social, a partir, por exemplo, das inúmeras certificações que na realidade constituem uma ilusão de qualificação para o mercado e de melhoria da empregabilidade, mas que, na verdade, cumprem o papel de convencer a classe trabalhadora de que esses cursos de curta duração lhes são importantes. Para essa lógica, se após o curso haverá inserção no mundo do trabalho não é a questão central. O importante é contribuir para conformar os trabalhadores aos interesses do capital.

Concluímos, ainda, que a privatização da EP, via Pronatec, se efetiva por meio de transferências diretas e indiretas de recursos públicos, pelo não engajamento do governo com a responsabilidade pela oferta pública e gratuita (privatização implícita), fazendo com que o setor privado seja imbuído de novas demandas (privatização por atribuição) e, fundamentalmente, pelo financiamento público da oferta privada por meio da bolsa-formação e do Fies.

O Pronatec sintetiza, nessa segunda década do século XXI, as relações entre o Estado e as políticas públicas educacionais, em particular as da EP, que se materializam no sentido de ampliar

${ }^{20}$ Para mais informações acessar: http://www.neweducation.com.br/produtos-e-servicos/pronatec-fic/. 
o acesso quantitativo aos fragmentos mais empobrecidos da classe trabalhadora à educação, mas não na perspectiva da garantia do direito pleno, inteiro. A ampliação do acesso ocorre de forma desigual de modo que para a maioria a entrada é por uma porta que leva a um horizonte restrito, por meio da expansão privatizante com recurso público que, ao mesmo tempo, treina o trabalhador para o trabalho simples e cuida para manter o mercado educacional aquecido.

Finalmente, é importante ter claro que mesmo diante do cenário de dificuldades aqui discutido, o Estado é um espaço de condensação de forças, de disputas cuja direção do movimento é decorrente dessas disputas e depende da correlação de forças, a qual não é estática nem linear. Nesse sentido, retomamos os parágrafos introdutórios deste texto nos quais discorremos, brevemente, sobre o movimento de expansão e interiorização da RFEP que vem proporcionando acesso à população das periferias das grandes cidades e dos rincões e grotões deste país a instituições educacionais reconhecidas como de qualidade.

Este é um movimento que embora também apresente problemas de concepção e de operacionalização, tem potencial de se tornar muito significativo para a educação da classe trabalhadora caso avance na direção de uma maior articulação com as outras esferas públicas educacionais e seja orientado pela concepção de formação humana integral.

É na disputa por uma concepção de formação humana e de expansão da EP diferentes das que estão postas no Pronatec que se poderá questioná-lo e, em alguma medida, contribuir para sua ressignificação.

\section{REFERÊNCIAS BIBLIOGRÁFICAS}

1. AZEVEDO, Janete Maria Lins de. Notas sobre a análise da gestão da educação e da qualidade do ensino no contexto das políticas educativas. Revista Brasileira de Política e Administração da Educação, v. 27, n. 3, p. 361-588, set./dez. 2011.

2. BRASIL. Discurso da presidenta da república, Dilma Rousseff, durante cerimônia de lançamento do programa nacional de acesso ao ensino técnico e ao emprego. 2011a. Disponível em: <http://www3.planalto.gov.br/imprensa/discursos/discurso-da-presidentada-republica-dilma-rousseff-durante-cerimonia-de-lancamento-do-programa-nacional-deacesso-ao-ensino-tecnico-e-ao-emprego>. Acesso em: 10 set. 2014.

3. BRASIL. Catálogo nacional dos cursos técnicos. 2012 Disponível em: <http://pronatec. mec.gov.br/cnct/pdf/tabela_convergencia.pdf>. Acesso em: 16 mar. 2015.

4. _. Guia Pronatec de Cursos FIC. 2013. Disponível em: <http://pronatec.mec.gov.br/fic/ pdf/2013_guia_cursosfic_port_899.pdf>. Acesso em: 16 mar. 2015.

5. __ Relatório de Auditoria Anual de Contas/2013 realizado pela CGU na Secretaria de Educação Profissional e Tecnológica. Brasília, 2014b.

6. ‥ Relatório de Gestão do Exercício de $\mathbf{2 0 1 3}$ da Secretaria de Educação Profissional e Tecnológica SETEC. Brasília, 2014c.

7. __ Fundo de Financiamento Estudantil. Disponível em: http://portal.mec.gov.br/in dex.php?option=com_content\&view=article\&id=198\&Itemid=303. Acesso em: 10 set. 2013

8. CUNHA, Luiz Antônio. O ensino industrial-manufatureiro no Brasil.

9. Revista Brasileira de Educação, n. 14, p. 89-107, maio-ago, 2000. Disponível em: 
<http://www.redalyc.org/articulo.oa?id=27501406>. Acesso em: 15 mar. 2015.

10. DEMO, Pedro. Educação e qualidade. Campinas: Papirus, 1996.

11. DRAIBE, Sônia M. As políticas sociais e o neoliberalismo: reflexões suscitadas pelas experiências latino-americanas. Revista USP, São Paulo, n. 17, p. 86-101, mar./maio 1993. Disponível em: <http://www.usp.br/revistausp/17/07-sonia.pdf>. Acesso em: 27 dez. 2013.

12. FRIGOTTO, Gaudêncio. A produtividade da escola improdutiva: um (re) exame das relações entre educação e estrutura econômico-social e capitalista. São Paulo. Cortez. 5. ed.1999 .

13. Capital humano. Dicionário da Educação Profissional em Saúde. Rio de Janeiro: Fundação Oswaldo Cruz/ Escola Politécnica de Saúde Joaquim Venâncio, 2009. Disponível em: < http://www.sites.epsjv.fiocruz.br/dicionario/verbetes/caphum.html >. Acesso em: 05 mar. 2015.

14. __ Ensino Médio e técnico profissional: disputa de concepções e precariedade. Le Monde Diplomatique Brasil, São Paulo, mar. 2013. Disponível em:<http://www.diplomatique.org.br/ artigo.php?id=1384>. Acesso em: 10 fev. 2015

15. FUNDAÇÃO GETÚLIO VARGAS. A educação profissional e você no mercado de trabalho. 2010, Rio de Janeiro: FGV/CPS.

16. GERMANO. O discurso político sobre a educação no Brasil autoritário. Revista Cedes, Campinas, vol. 28, n. 76, p. 313-332, set./dez. 2008. Disponível em <http://www.cedes.uni camp.br>. Acesso em 3 jul. 2015.

17. GLOBO. Fusão da Anhanguera e Kroton cria a 17a maior empresa da Bovespa. 2014. Disponível em: < http://g1.globo.com/economia/mercados/noticia/2014/07/fusao-da-anhan guera-e-kroton-cria-17-maior-empresa-da-bovespa.html>. Acesso em: 1 jun 2015.

18. GUIMARÃES, Cátia. Capital financeiro avança sobre a Educação Profissional. Revista Poli: Saúde, Educação e Trabalho, Rio de Janeiro, v. 35, n. 6, p.16-18, ago. 2014. Disponível em: <http://www.epsjv.fiocruz.br/sites/default/files/revista_poli_-_35.pdf >. Acesso: $10 \mathrm{dez}$. 2014.

19. GRABOWSKI, Gabriel. Financiamento da educação profissional no brasil: Contradições e desafios. Porto Alegre, 2010. 216f. Tese. (Doutorado em Educação) - Universidade Federal do Rio Grande do Sul, Porto Alegre, 2010. Disponível em: <http://repositorio.min edu.gob.pe/bitstream/handle/123456789/621/2010_Grabowski_Financiamento\%20da\%20e duca\%C3\%A7\%C3\%A3o\%20profissional\%20no\%20Brasil\%20\%20contradi\%C3\%A7\%C3\%B5es \%20e\%20desafios.pdf?sequence=1\&isAllowed=y> Acesso em: 6 jan de 2015 .

20. HARVEY, David. A condição pós-moderna. São Paulo. Loyola.1993, p. 117-162.

21. INSTITUTO BRASILEIRO DE GEOGRAFIA E ESTATíStICA. Pesquisa Mensal de Emprego Abril 2015. 2015. Disponível em: <ftp://ftp.ibge.gov.br/Trabalho_e_Rendimento/Pesquisa_ Mensal_de_Emprego/fasciculo_indicadores_ibge/2015/pme_201504pubCompleta.pdf> Acesso em: 25 mai. 2015.

22. LIMA, Marcelo. A educação profissional no governo Dilma: Pronatec, PNE e DCNEMs. Revista Brasileira de Política e Administração da Educação, ANPAE, v. 28, n. 2, p. 495-513 maio 2012.

23. LIMA FILHO, Domingos Leite. Expansão da educação superior e da educação profissional no Brasil: tensões e perspectivas. Revista Educação em Questão Natal, v. 51, n. 37, p. 195-223, jan./abr. 2015. 
24. LÔBO, Adriene de Faria. A prerrogativa constitucional referente à imunidade tributária concedida às entidades de educação e de assistência social. Brasília, 2013. Instituto Brasiliense de Direito Público. Disponível em: <http://dspace.idp.edu.br:8080/xmlui/bit stream/handle/123456789/1350/Artigo_ADRIENE\%20DE\%20FARIA\%20LOBO.pdf?sequence= 1>. Acesso em: 25 mai. 2015.

25. MACHADO, M. Maria; GARCIA, L. T.. Passado e presente na formação de trabalhadores jovens e adultos. Revista Brasileira de Educação de Jovens e Adultos, v. 1, p. 45-64, 2013.

26. MOROSINI, M. C. Estado do conhecimento sobre internacionalização. Educar em Revista. Curitiba: UFPR, n. 28, p. 107-124, 2006.

27. MOURA, Dante Henrique. Ensino médio e educação profissional nos anos 2000: movimentos contraditórios. In: (Org.). Produção de conhecimento, políticas públicas e formação docente em educação profissional. Porto Alegre: Mercado das letras, 2013.

28. NEVES, L. M. W. O Mercado do Conhecimento e o Conhecimento Para o Mercado. Rio de Janeiro: Fiocruz, 2008.

29. NEW EDUCATION. Seminário PRONATEC 12-Set-2014. 2014. Disponível em: $<$ http://www.neweducation.com.br/fale-conosco-neweducation/seminario-pronatec-12-set2014/>.

30. O'CONNOR, James. USA, a crise do Estado capitalista. Rio de Janeiro: Paz e Terra, 1977.

31. OLIVEIRA, Ramon de. Empregabilidade. Dicionário da Educação Profissional em Saúde. Rio de Janeiro: Fundação Oswaldo Cruz/ Escola Politécnica de Saúde Joaquim Venâncio, 2009. Disponível em: <http://www.sites.epsjv.fiocruz.br/dicionario/verbetes/emp.html>. Acesso em: 05 mar. 2015.

32. SALDANHA, Letícia de Luca Wollmann. O Pronatec e a relação ensino médio e educação profissional. 2012. Disponível em: <http://www.ucs.br/etc/conferencias/index.php/anpedsul /9anpedsul/paper/viewFile/1713/141>. Acesso em: 6 jan de 2015.

33. SCHULTZ, T. O capital humano: investimento em educação e pesquisa. Trad. de Marco Aurélio de M. Matos. Rio de Janeiro. Zahar, p. 31-52, 1973.

34. SILVA, Danilma de Medeiros. Desvelando o PRONATEC: uma avaliação política do programa. Natal, 2015. 168f. Dissertação. (Mestrado em Educação) - Universidade Federal do Rio Grande do Norte, Natal, 2015. 